Atualidades de Pesquisa

\title{
DA CRIANÇA A MATAR À MORTE DA CRIANÇA: REFLEXÕES PSICANALÍTICAS SOBRE A MEDICALIZAÇÃO NA INFÂNCIA
}

Tese de Doutorado no Instituto de Psicologia da Universidade de São Paulo

\author{
Autora \\ Michele Kamers \\ Orientadora \\ Profa. Dra. Maria Cristina Machado Kupfer \\ (Universidade de São Paulo)
}

Banca Examinadora

Prof. Dr. Rinaldo Voltolini (Universidade de São Paulo), Prof. Dr. Mário Eduardo Costa Pereira (Universidade Estadual de Campinas), Profa. Dra. Angela Maria Resende Vorcaro (Universidade Federal de Minas Gerais), Profa. Dra. Miriam Debieux Rosa (Universidade de São Paulo) 
A partir da investigação dos determinantes históricos e sociais que transformaram a escola em um dispositivo regulador da inclusão da criança no domínio do saber médico psiquiátrico, busca-se discutir o lugar e a função que a medicalização na infância tem ocupado no laço social, fundamentalmente, para as instituições que se ocupam da criança na atualidade. Para tanto, retoma de que maneira se produziu a constituição de um saber e de discursos psicológicos e psiquiátricos sobre a criança, investigando de que maneira esses discursos produzem obstáculos ao processo educativo e civilizatório, numa lógica em que o mal-estar, quando não reconhecido, retorna ao discurso sob a forma de patologia. Ocasião em que a criança é transformada em objeto de amor eterno ou de pesquisa científica, impedindo a morte da representação narcísica primária do infans no laço social que, organizado a partir do discurso da ciência e do capitalismo, sustenta a promessa do encontro entre o ideal e o sujeito numa lógica em que a medicalização sustenta a possibilidade de realização dessa promessa, mesmo às custas da morte do sujeito. 